\title{
VALVE REPLACEMENT WITH A STENTLESS BIOPROSTHESIS: VERSATILITY OF THE PORCINE AORTIC ROOT
}

Stephen Westaby, MS, FRCS

Xu Y. Jin, MD

Takahiro Katsumata, MD, PhD

Ahmed Arifi, FRCS

Peter Braidley, FRCS

\begin{abstract}
Objective: Stentless valves convey important hemodynamic benefits but are used selectively depending on aortic root structure. The Freestyle valve (Medtronic, Inc, Minneapolis, Minn) is a versatile device that can be implanted by different methods depending on operating conditions. We aimed to demonstrate that a stentless valve could be used in every patient without increased risk of morbidity or mortality. We documented the effects of this valve on clinical outcome and left ventricular mechanics. Methods: The Freestyle valve was implanted by the modified subcoronary method into 200 consecutive unselected patients who received a tissue valve in the aortic position and by root replacement in 2 . Forty-three percent were older than 75 years. Forty percent underwent coronary bypass. Detailed clinical and echocardiographic follow-up (Food and Drug Administration protocol) was used out to 3 years. Results: Mean ischemic time was $43 \pm 6$ minutes for isolated aortic valve replacement and $63 \pm 14$ minutes with concomitant procedures. Thirty-day mortality was $6 \%$, none of the deaths being valve related. Hemodynamic function improved progressively with falling valve gradients and increased effective orifice areas. Left ventricular mass fell within normal limits over 2 years, but at 3 years there was a non-valve-related upswing. No instances of valve thrombosis, hemolysis, or paravalvular leak were noted. Less than $5 \%$ had mild to moderate aortic regurgitation. Conclusions: The Freestyle valve can be used in virtually every patient with aortic valve disease and provides superlative hemodynamic outcome. Hospital mortality and morbidity are similar to those reported for stented valves in an elderly population. (J Thorac Cardiovasc Surg 1998;116:477-84)
\end{abstract}

$A^{\text {onten }}$ ortic valve disease in elderly patients is dominated by calcific aortic stenosis. For worthwhile event-free survival at great age it is important to achieve rapid improvement in ventricular mechanics, functional class, and quality of life without surgical or valve-related morbidity. ${ }^{1,2}$ The type of prosthesis has an important bearing on postoperative left ventricular function, particularly in smaller sizes. ${ }^{3,4}$ Stentless aortic bioprostheses convey important hemodynamic benefits, in contrast to the

From the Department of Cardiac Surgery, Oxford Heart Centre, The John Radcliffe Hospital, Oxford, United Kingdom.

Received for publication Jan 22, 1998; revisions requested April 8, 1998; revisions received April 24, 1998; accepted for publication June 2, 1998.

Address for reprints: Stephen Westaby, BSc, FRCS, MS, Oxford Heart Centre, John Radcliffe Hospital, Headley Way, Headington, Oxford OX3 9DU, United Kingdom.

Copyright (c) 1998 by Mosby, Inc.

$0022-5223 / 98 \$ 5.00+0 \quad \mathbf{1 2 / 1 / 9 2 3 0 9}$ nonphysiologic flow profile and residual pressure gradients across mechanical valves or stented bioprostheses. ${ }^{5,6}$ Just as homograft or pulmonary autograft aortic valve replacement results in rapid resolution of left ventricular hypertrophy in the young, similar benefits are achieved for the elderly with stentless xenografts. ${ }^{1,6}$ Nevertheless, their widespread use has been restricted by perceived difficulties of implantation with prolonged myocardial ischemic and cardiopulmonary bypass times. Consequently, we sought to address the criticism that stentless valves are suitable only for selected patients without aortic root calcification or discrepancy between the diameters of the anulus and sinotubular junction. This article describes our experience, including the learning curve, in 202 consecutive unselected patients, operated on by 1 surgeon $(\mathrm{S} . \mathrm{W}$.$) , who received a bioprosthesis in the$ aortic position. During this series no patient older than 70 years received a mechanical valve, and no patient received a stented bioprosthesis. 


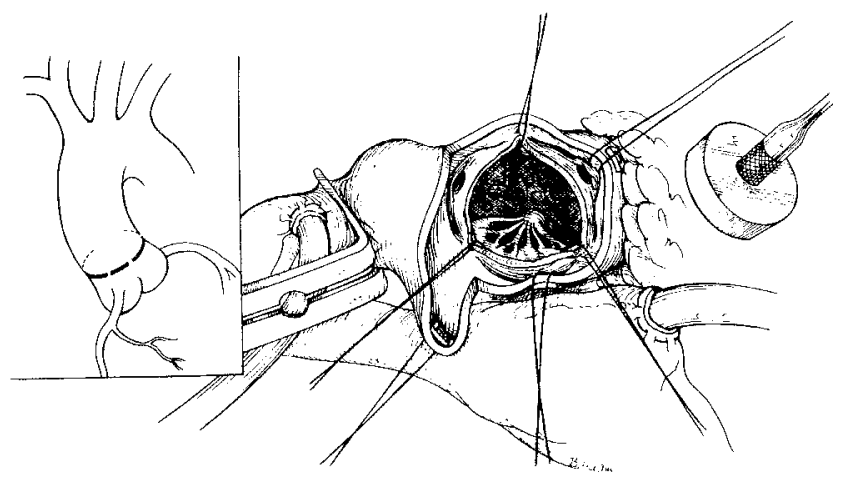

A
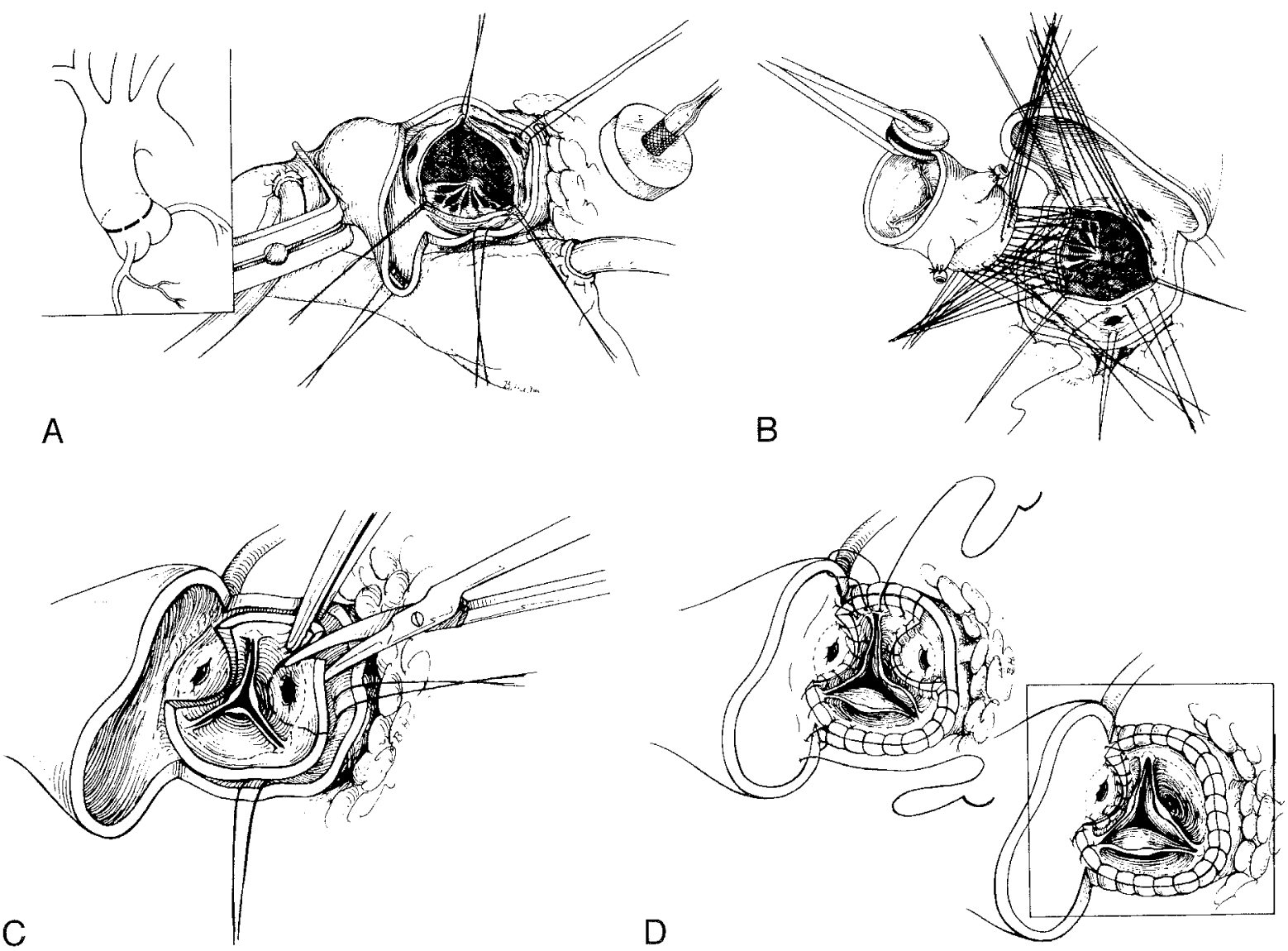

Fig. 1. Technical aspects of Freestyle valve implantation. A, Transverse aortotomy with stay sutures in place and the first valve sutures at the base of the inner leaflet triangle. Valve size is chosen to fit the anulus and fill the aortic root. B, Simple interrupted valve sutures in the anulus and valve inflow. The porcine coronaries are closer together than in the human coronary ostia. $\mathbf{C}$, The porcine aortic sinuses (left and right) are removed after the valve inflow sutures are tied. This cnsures accurate apposition without commissural distortion. D, The outflow suture line joins the crest of the trimmed Freestyle valve to the transverse aortotomy. In the event of an occluded right coronary ostium and coronary bypass, the right coronary sinus need not be excised. Closure of the aortotomy effectively "suspends" the valve within the aortic root and prevents cusp prolapse.

\section{Patients and methods}

The series comprised 115 male $(57 \%)$ and 87 female $(43 \%)$ patients aged 30 to 86 years. Mean age at implantation was 73 years. Only 18 patients (9\%) were younger than 65 years. These were patients who declined a mechanical valve or would not accept anticoagulation with warfarin. Eighty-seven patients $(43 \%)$ were older than 75 years of age. One hundred forty-two $(70 \%)$ were in New York Heart Association (NYHA) class III or IV. One hundred sixty-one patients $(80 \%)$ were in sinus rhythm and 2 had a pre-existing pacemaker for heart block. The remainder had atrial fibrillation or flutter. One hundred ten patients $(55 \%)$ had coronary artery disease and 81 $(40 \%)$ underwent concomitant coronary artery surgery. One hundred eighty-four patients $(91 \%)$ had critical aortic stenosis, of whom $47(23 \%)$ had an element of aortic regurgitation. The remainder were operated on for severe aortic regurgitation. Two patients had active native valve endocarditis and 1 had an acute type $A$ dissection. ${ }^{7}$ Eleven patients underwent reoperation for a failed bioprosthesis $(n=9)$, mechanical valve $(n=1)$, or homograft. $(n=1)$. With informed consent and ethical committee approval, all patients were prospectively entered into a clinical trial approved by the US Food and Drug Administration (FDA) with detailed serial echocardiographic follow-up.

Surgical methods. In 200 patients the porcine aortic cylinder (Freestyle valve, Medtronic, Inc, Minneapolis, Minn) was implanted by the modified subcoronary technique described by the author ${ }^{8}$ (Fig. $1, A$ to $D$ ). This method was used irrespective of the degree and extent of calcification or discrepancy between annular size and sinotubular junction for these patients. Two patients underwent aortic root replacement for "porcclain" aorta, 
Table I. Mortality and valve-related morbidity after Freestyle valve replacement

\begin{tabular}{|c|c|c|c|c|c|c|}
\hline \multirow[b]{2}{*}{ Items } & \multicolumn{2}{|c|}{$\begin{array}{l}\text { Early } \\
\text { events* }\end{array}$} & \multicolumn{2}{|c|}{$\begin{array}{l}\text { Late } \\
\text { eventst }\end{array}$} & \multicolumn{2}{|c|}{$\begin{array}{l}\text { Freedom from } \\
\text { event (1 yr)t }\end{array}$} \\
\hline & $n$ & $\%$ & $n$ & $\%$ & $\%$ & $\begin{array}{l}\text { Standard } \\
\text { error }\end{array}$ \\
\hline All deaths & 12 & 6.0 & 16 & 6.1 & 88.2 & 2.5 \\
\hline Cardiac deaths & 3 & 3.0 & 3 & 1.1 & 95.2 & 1.7 \\
\hline $\begin{array}{l}\text { Permanent neurologic } \\
\text { event }\end{array}$ & 5 & 2.5 & 0 & 0 & 97.2 & 1.2 \\
\hline $\begin{array}{l}\text { Transient neurologic } \\
\text { event }\end{array}$ & 1 & 0.5 & 1 & 0.4 & 99.4 & 0.6 \\
\hline Valve thrombosis & 0 & 0 & 0 & 0 & 100 & 0 \\
\hline Hemolysis & 0 & 0 & 0 & 0 & 100 & 0 \\
\hline Paravalvular leak & 0 & 0 & 0 & 0 & 100 & 0 \\
\hline Endocarditis & 0 & 0 & 1 & $0.4 \S$ & 99.3 & 0.7 \\
\hline $\begin{array}{l}\text { Anticoagulation-related } \\
\text { bleeding }\end{array}$ & 2 & 1.0 & 2 & 0.8 & 97.5 & 1.2 \\
\hline Reoperation & 0 & 0 & 2 & $0.3 \S$ & 98.8 & 0.9 \\
\hline
\end{tabular}

*Within 30 days of operation, percent of 202 patients.

$\uparrow$ Events after 30 days, rate calculated as percent per patient-year (linearized rate over 266 cumulated patient-years excluding the first 30 days of implant).

Freedom from the first event was calculated using the life table method with intervals of 1 month and one-quarter year. $n$, number of patients.

$\S$ One reoperation was for endocarditis, in the same patient.

which followed dense mediastinal irradiation for breast cancer.

Both surgical techniques have been described in detail, ${ }^{8}$ but with increasing experience some key points are worth reiterating. For the modified subcoronary method the valve size is chosen to provide a snug fit within the human aortic root. In some patients it may be difficult to accommodate the height of the inflow Dacron cloth beneath the porcine right coronary artery under the human right coronary artery. Distortion through bending of the Freestyle inflow may cause obstruction, prosthetic regurgitation, or contact of the xenograft cusp with the Dacron fabric (Fig. 2). Avoidance of this problem is part of the surgical learning curve. In 12 patients $(6 \%)$ we rotated the valve so that the elevated part of the Dacron cloth was positioned in the human noncoronary sinus. When the right coronary ostium was completely occluded $(n=9$; $4.5 \%$ ), the porcine right coronary sinus was left intact and a bypass graft constructed to the distal right coronary artery.

Valve sizing relied entirely on the native valve anulus size after valve excision and decalcification. The diameter of the sinotubular junction was irrelevant because this part of the human aorta was tailored to fit the outflow of the Freestyle valve. The porcine noncoronary sinus was left intact to ensure accurate alignment of the 2 attached commissures, which simplifies alignment of the third. The mean valve size implanted was $23.4 \pm 1.9 \mathrm{~mm}$. Only 3 patients $(1.5 \%)$ received a size 19 valve and $23(11.5 \%)$ a $27-\mathrm{mm}$ valve. For the patient with acute type A dissection, the modificd subcoronary method was used to exclude the dissected tissues, and then the ascending aorta was re-
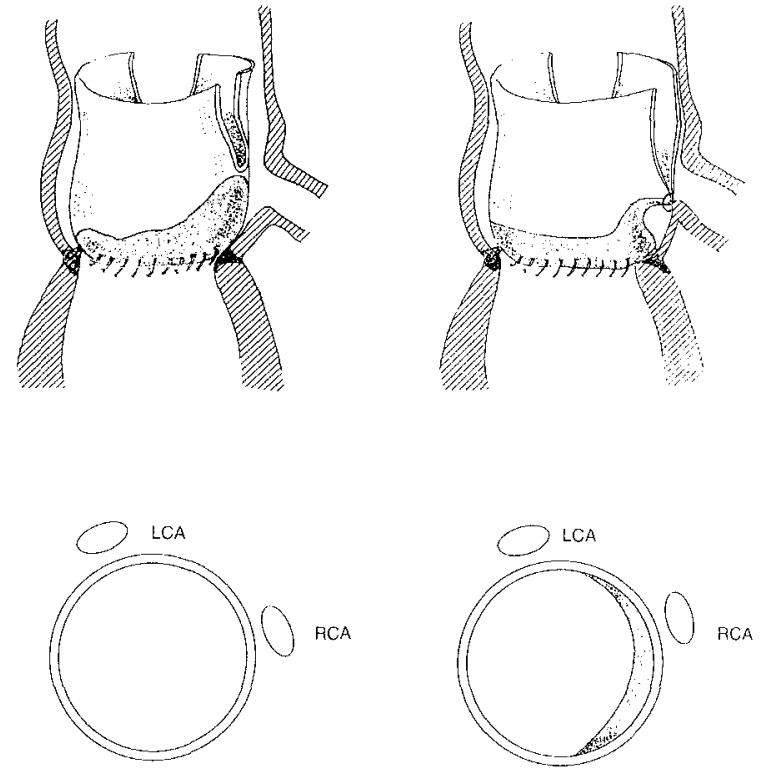

Fig. 2. Potential for a technical error, which produces an elevated transvalvular gradient after Freestyle valve implantation. If the distance between the valve anulus and right coronary ostium is less than the height of the inflow cloth beneath the porcine right coronary, the cloth may be buckled. This can be avoided by rotating the porcine right coronary sinus to the human noncoronary sinus. $R C A$, Right coronary artery; $L C A$, left coronary artery.

placed with a 26-mm Dacron graft (Hemashield, Meadox Medicals, Inc, Oakland, NJ). ${ }^{7}$

We initially elected to prescribe warfarin for all patients for 3 months, aiming for an international normalized ratio (INR) of 2.0 to 2.5 for paticnts in sinus rhythm. Those in atrial fibrillation were administered anticoagulants continuously to maintain an INR of 2.5 to 3.5 unless atrial fibrillation reverted to sinus rhythm. However, when 2 patients older than 80 years had anticoagulant-related cerebral hemorrhage (Table I), we reverted to a policy of using only aspirin, $75 \mathrm{mg}$ daily, for patients in sinus rhythm. In total, 84 patients $(42 \%)$ received warfarin and $29(15 \%)$ received neither warfarin nor aspirin.

Follow-up studies. All patients were subject to detailed clinical and echocardiographic follow-up at intervals of 6 and then 12 months according to FDA guidelines for valve studies.

Echocardiography. Transthoracic echocardiography was performed at the time of discharge from the hospital and then at 6 months, 12 months, and annually. Echocardiograms were recorded with the Toshiba $380 \mathrm{~A}$ echocardiographic system, with a 2.5-MHZ phased-array transducer (Toshiba Corp, Tokyo, Japan). The protocols were described previously in detail. ${ }^{9}$ Standard left ventricular M-mode echocardiograms were recorded and stored on videotape at a speed of $50 \mathrm{~mm} / \mathrm{s}$, with simultaneous electrocardiogram and phonocardiogram. From an apical 5 -chamber view, flow velocities in the outflow tract $(2.5$ 
Table II. Changes in left ventricular hemodynamics, stentless valve performance, and ventricular mass index during follow-up (mean $\pm S D$ )

\begin{tabular}{|c|c|c|c|c|c|c|}
\hline \multirow[b]{2}{*}{ Variables } & \multicolumn{5}{|c|}{ Time after AVR (mo) } & \multirow{2}{*}{$\frac{\text { One-way ANOVA }}{P \text { value }}$} \\
\hline & Discharge $(n=146)$ & $6(n=108)$ & $12(n=109)$ & $24(n=84)$ & $36-48(n=50)$ & \\
\hline Heart rate (beats/min) & $82 \pm 17$ & $74 \pm 13^{*}$ & $73 \pm 13^{*}$ & $69 \pm 11^{*}$ & $68 \pm 13^{*}$ & $<.001$ \\
\hline Systolic BP (mm Hg) & $138 \pm 22$ & $136 \pm 19$ & $139 \pm 21$ & $148 \pm 22 *$ & $146 \pm 26^{*}$ & $=.001$ \\
\hline LV SVI $\left(\mathrm{ml} / \mathrm{m}^{2}\right)$ & $35 \pm 12.9$ & $35 \pm 12.6$ & $38 \pm 11.8$ & $43 \pm 14.7^{*}$ & $43 \pm 11.9^{*}$ & $<.001$ \\
\hline LVOT area $\left(\mathrm{cm}^{2}\right)$ & $3.4 \pm 1.0$ & $3.3 \pm 0.7$ & $3.3 \pm 0.8$ & $3.4 \pm 0.8$ & $3.3 \pm 0.9$ & $=.644$ \\
\hline LVOT TVI $(\mathrm{cm})$ & $19 \pm 5.7$ & $20 \pm 5.9$ & $21 \pm 5.6^{*}$ & $24 \pm 6.9^{k}$ & $24 \pm 5.7^{*}$ & $<.001$ \\
\hline AV peak velocity $(\mathrm{cm} / \mathrm{s})$ & $220 \pm 52$ & $195 \pm 45^{*}$ & $193 \pm 50^{*}$ & $199 \pm 53^{*}$ & $199 \pm 50^{*}$ & $<.001$ \\
\hline AV TVI (cm) & $35 \pm 9.2$ & $36 \pm 10.7$ & $36 \pm 11.0$ & $37.8 \pm 11.9$ & $37.7 \pm 11.1$ & $=.308$ \\
\hline $\operatorname{AV} \operatorname{EOA}\left(\mathrm{cm}^{2}\right)$ & $1.9 \pm 0.83$ & $1.9 \pm 0.62$ & $2.0 \pm 0.70$ & $2.2 \pm 0.77^{*}$ & $2.2 \pm 0.73^{*}$ & $=.002$ \\
\hline Mean AV PG (mm Hg) & $7.5 \pm 4.7$ & $5.4 \pm 3.1^{*}$ & $5.2 \pm 3.5^{*}$ & $5 . .3 \pm 3.8^{*}$ & $5.2 \pm 3.9^{*}$ & $<.001$ \\
\hline EOA/LVOT area $(\%)$ & $56 \pm 15.9$ & $56 \pm 11.9$ & $60 \pm 13.7^{*}$ & $64 \pm 12.8^{*}$ & $67 \pm 12.2^{*}$ & $<.001$ \\
\hline $\mathrm{T} / \mathrm{R}$ ratio & $0.59 \pm 0.20$ & $0.50 \pm 0.18 *$ & $0.45 \pm 0.11^{*}$ & $0.45 \pm 0.14^{*}$ & $0.52 \pm 0.13^{*}$ & $<.001$ \\
\hline $\mathrm{LV} \mathrm{MI}\left(\mathrm{g} / \mathrm{m}^{2}\right)$ & $146 \pm 55$ & $125 \pm 41^{*}$ & $109 \pm 38^{*}$ & $109 \pm 39^{*}$ & $128 \pm 51^{*}$ & $<.001$ \\
\hline $\mathrm{LV}$ SWI $\left(\mathrm{mJ} / \mathrm{m}^{2}\right)$ & $475 \pm 179$ & $471 \pm 174$ & $510 \pm 167$ & $592 \pm 234 *$ & $555 \pm 194^{*}$ & $<.001$ \\
\hline Myocardial SW $\left(\mathrm{mJ} / \mathrm{cm}^{3}\right)$ & $3.6 \pm 1.68$ & $4.1 \pm 1.90$ & $5.2 \pm 2.38^{*}$ & $5.8 \pm 2.42 *$ & $4.8 \pm 1.92^{*}$ & $<.001$ \\
\hline
\end{tabular}

$A V R$, Freestyle aortic valve replacement; $A N O V A$, one-way analysis of variance with respect to time; $n$, number of echo study at each time point; $L V$, left ventricle; $S V I$, stroke volume index; $L V O T$, left ventricular outflow tract; $T V$, time integral of flow vclocity; $E O A$, effective orifice area; $T / R$, wall thickness to cavity radius; $M I$, mass index; $S W I$, stroke work index.

Significantly different from 0.5 month by $95 \%$ confidence interval.

MHZ pulsed Doppler ultrasonography) and the maximum velocity across the stentless valve ( $2.5 \mathrm{MHZ}$ continuous wave Doppler ultrasonography) were recorded at a speed of $100 \mathrm{~mm} / \mathrm{s}$ for off-line analysis. ${ }^{10,11}$ Systemic blood pressure was also recorded noninvasively by the Hewlett-Packard 66s hemodynamic monitoring system (Hewlett-Packard Company, Andover, Mass).

Mean values for each measurement were derived from 3 heartbeats in patients in sinus rhythm and from 5 beats in those with atrial fibrillation or a VVI pacemaker. End-diastolic dimension, septum thickness, posterior wall thickness, and end-systolic dimension were measured from $\mathrm{M}$-mode echocardiograms. Dimensional shortening fraction, ejection fraction, and the ratio of the wall thickness to cavity radius at end-diastole were determined according to the criteria of the American Society of Echocardiography. ${ }^{12}$ Left ventricular muscle mass was calculated $^{12,13}$ and indexed to the body surface area. Mean flow velocities and the time integral of systolic flow velocities in the left ventricular outflow tract and those of the aortic valve were derived from the Doppler recordings. ${ }^{10,11,14}$ Left ventricular stroke volume was calculated as the product of the cross-sectional area and flow-velocity time-integral in the outflow tract. The effective orifice area of the aortic valve was calculated by the continuity equation ${ }^{11}$ and indexed to the cross-sectional area of the outflow tract. Mean pressure drop across the aortic valve was calculated from the simplified Bernoulli equation by taking the subvalvular $\left(V_{1}\right)$ and valvular $\left(V_{2}\right)$ mean velocities (mean pressure drop $=4\left(\mathrm{~V}_{2}{ }^{2}--\mathrm{V}_{1}{ }^{2}\right)$, in millimeters of mercury." Left ventricular stroke volume index and cardiac index were calculated from stroke volume (LVSV), heart rate, and body surface area. Left ventricular stroke work, measured in millijoules, was determined by LVSV $\times$ (mean arterial pressure + mean net aortic valve pressure drop) $\times 0.0136 \times 9.8$ and indexed to body surface area (millijoules per square meter). ${ }^{9}$ Myocardial stroke work was defined as global stroke work divided by muscle mass volume (millijoules per cubic millimeter). ${ }^{15}$

Statistical analysis. Echocardiographic and hemodynamic data are presented as mean \pm 1 standard deviation. Data were analyzed by means of MINITAB statistical software (Release 11 for Windows, 1996; Minitab Inc, State College, $\mathrm{Pa}){ }^{16}$ One-way analysis of variance was performed to test the significance of changes in each measurement over the follow-up time. When this was significant, a further comparison of $95 \%$ confidence intervals with respect to the discharge echocardiographic study was carried out by means of Dunnett's method, with an overall error rate of 0.05 and an individual error rate of 0.02 . The changes in valve performance, left ventricular mass index, and ejection fraction over follow-up time and across different valve sizes were examined by 2 -way analysis of variance.

\section{Results}

For the 113 patients undergoing isolated aortic valve replacement, the mean crossclamp time was 43 \pm 6.0 minutes (range, $34-60$ minutes). In 85 patients undergoing concomitant procedures the crossclamp time was $63 \pm 14$ minutes (range, 34-123 minutes). In no patient was an implant abandoned or the valve size changed.

Clinical outcomes. Twelve deaths occurred $(6 \%$ hospital mortality) within 30 days of the operation (Table I). Three perioperative deaths occurred as a result of acute myocardial infarction in elderly patients (>75 years) with aortic stenosis, left ventricular hypertrophy, and severe diffuse coronary artery disease. Two patients died on the second postoper- 
Table III. Changes in mean valvular pressure gradient and effective orifice area during follow-up time $($ mean $\pm S D)$

\begin{tabular}{|c|c|c|c|c|c|c|c|}
\hline \multirow[b]{2}{*}{ Variable/valve size } & \multicolumn{5}{|c|}{ Time after $A V R$} & \multicolumn{2}{|c|}{ Two-way ANOVA } \\
\hline & Discharge & $3-6$ mo & $12 m o$ & $24 m o$ & $36-48 \mathrm{mo}$ & Versus time & Versus size \\
\hline Mean pressure gradient ( $\mathrm{mm} \mathrm{Hg}$ ) & & & & & & $P<.001$ & $P<.001$ \\
\hline $21 \mathrm{~mm}(n=122)$ & $11.9 \pm 0.6$ & $8.0 \pm 0.6$ & $8.2 \pm 0.6$ & $8.4 \pm 0.7$ & $8.2 \pm 0.9$ & & \\
\hline $23 \mathrm{~mm}(n=164)$ & $7.7 \pm 0.5$ & $5.4 \pm 0.6$ & $5.0 \pm 0.6$ & $4.5 \pm 0.6$ & $4.7 \pm 0.7$ & & \\
\hline $25 \mathrm{~mm}(n=153)$ & $5.6 \pm 0.5$ & $4.0 \pm 0.5$ & $4.0 \pm 0.5$ & $3.4 \pm 0.7$ & $3.7 \pm 1.0$ & & \\
\hline $27 \mathrm{~mm}(n=58)$ & $4.5 \pm 0.8$ & $3.7 \pm 0.9$ & $2.7 \pm 0.9$ & $4.1 \pm 1.0$ & $2.8 \pm 1.3$ & & \\
\hline Effective orifice area $\left(\mathrm{cm}^{2}\right)$ & & & & & & $P<.001$ & $P<.001$ \\
\hline $21 \mathrm{~mm}(n=122)$ & $1.37 \pm 0.11$ & $1.39 \pm 0.12$ & $1.42 \pm 0.12$ & $1.63 \pm 0.12$ & $1.71 \pm 0.17$ & & \\
\hline $23 \mathrm{~mm}(n=164)$ & $1.72 \pm 0.10$ & $1.78 \pm 0.10$ & $1.93 \pm 0.11$ & $2.09 \pm 0.12$ & $2.04 \pm 0.14$ & & \\
\hline $25 \mathrm{~mm}(n=153)$ & $2.28 \pm 0.10$ & $2.12 \pm 0.10$ & $2.29 \pm 0.10$ & $2.60 \pm 0.13$ & $2.66 \pm 0.19$ & & \\
\hline $27 \mathrm{~mm}(n=58)$ & $2.65 \pm 0.19$ & $2.25 \pm 0.15$ & $2.85 \pm 0.18$ & $3.02 \pm 0.19$ & $3.17 \pm 0.25$ & & \\
\hline
\end{tabular}

$\overline{A V R}$, Frestyle aortic valve replacement; $A N O V A$, analysis of variance; $n$, number of cho studies of each valve size.

Table IV. Changes in left ventricular mass index and ejection fraction during follow-up time (mean $\pm S D)$

\begin{tabular}{|c|c|c|c|c|c|c|c|}
\hline \multirow[b]{2}{*}{ Variable/valve size } & \multirow[b]{2}{*}{ Discharge } & \multicolumn{3}{|c|}{ Time after $A V R$} & \multirow[b]{2}{*}{$36-48$ months } & \multicolumn{2}{|c|}{ Two-way ANOVA } \\
\hline & & 6 months & 12 months & 24 months & & Versus time & Versus size \\
\hline $\mathrm{LV}$ mass index $\left(\mathrm{g} / \mathrm{m}^{2}\right)$ & & & & & & $P<.001$ & $P<.001$ \\
\hline $21 \mathrm{~mm}(n=122)$ & $127 \pm 8.1$ & $116 \pm 8.5$ & $105 \pm 8.4$ & $95 \pm 8.8$ & $106 \pm 11.7$ & & \\
\hline $23 \mathrm{~mm}(n=164)$ & $144 \pm 6.0$ & $124 \pm 7.9$ & $104 \pm 7.6$ & $109 \pm 8.4$ & $128 \pm 10.1$ & & \\
\hline $25 \mathrm{~mm}(n=153)$ & $150 \pm 6.5$ & $124 \pm 7.3$ & $106 \pm 7.2$ & $112 \pm 9.3$ & $129 \pm 13.2$ & & \\
\hline $27 \mathrm{~mm}(n=58)$ & $181 \pm 11.1$ & $153 \pm 12.3$ & $142 \pm 12.7$ & $134 \pm 13.2$ & $167 \pm 17.9$ & & \\
\hline \multicolumn{8}{|c|}{ LV ejection fraction $(\%)$} \\
\hline $21 \mathrm{~mm}(n=122)$ & $64.8 \pm 2.6$ & $65.0 \pm 2.7$ & $66.6 \pm 2.7$ & $67.0 \pm 2.8$ & $65.8 \pm 3.7$ & $P=.103$ & $P<.001$ \\
\hline $23 \mathrm{~mm}(n=164)$ & $56.5 \pm 1.9$ & $62.3 \pm 2.5$ & $63.1 \pm 2.4$ & $64.4 \pm 2.7$ & $61.9 \pm 3.2$ & & \\
\hline $25 \mathrm{~mm}(n=153)$ & $53.1 \pm 2.1$ & $56.4 \pm 2.3$ & $57.5 \pm 2.3$ & $57.8 \pm 3.0$ & $62.3 \pm 4.2$ & & \\
\hline $27 \mathrm{~mm}(n=58)$ & $51.5 \pm 3.4$ & $51.3 \pm 3.9$ & $58.1 \pm 4.0$ & $54.9 \pm 4.2$ & $46.2 \pm 5.7$ & & \\
\hline
\end{tabular}

ative day, 1 of an extensive perioperative cerebrovascular accident (CVA) and the second of left ventricular failure; the second death occurred in at moribund octogenarian (NYHA class IV) with aortic regurgitation and a "bovine" heart. The remaining patients died of stroke, mesenteric ischemia, or acute myocardial infarction between 8 and 21 days after the operation. A further 3 patients (all preoperatively in NYHA class IV or $V$ ) required intraaortic balloon pump support for between 2 and 7 days after the operation for impaired left ventricular function without perioperative myocardial infarction. These patients survived with fully competent aortic valves.

There were $16(8 \%)$ late deaths, 4 of which were cardiac in origin. Two occurred as a result of myocardial infarction 2 and 8 months after the operation, 1 was caused by acute type A dissection 30 months after valve replacement, and the last was caused by a stroke 4 months after the operation. Because this last patient, 77 years old, did not have an autopsy, the death was considered to be related to the study valve. Other deaths occurred as a result of malignant disease $(n=4)$, primary respiratory problems $(n=3)$, ruptured abdominal aortic aneurysm $(n=1)$, or were unexplained sudden deaths, presumed arrhythmia in patients all of whom underwent autopsy to rule out other valve-related disease. Of the 194 hospital survivors, $143(74 \%)$ remained in sinus rhythm. There were 39 patients $(20 \%)$ in atrial fibrillation, and 10 new patients required a pacemaker $(5 \%)$. Of 111 patients assessed at 1 year, $81 \%$ were in NYHA class I and $19 \%$ were in NYHA class II. Valve-related morbidity is summarized in Table I. All neurologic events and anticoagulantrelated hemorrhage are included in this table.

Hemodynamic performance of the Freestyle valve. From the 194 patients discharged from the hospital, 497 echocardiograms were obtained with adequate image quality for comprehensive hemodynamic analysis. This included 146 echoes at discharge, 108 at 6 months, and 109, 84, and 50 echoes 


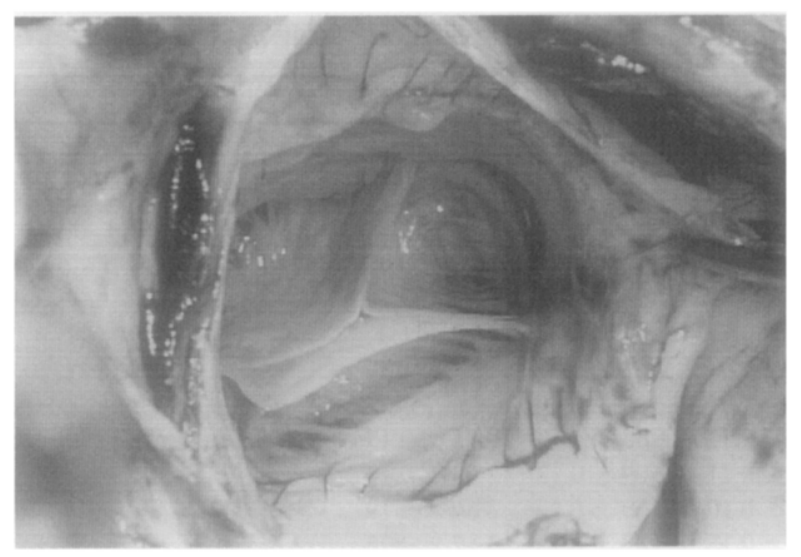

Fig 3. Freestyle valve 2 years after implantation (photographed during an operation for acute type A dissection. The valve was conserved).

at 1,2 , and 3 to 4 years, respectively, after implantation. These figures corresponded to $77 \%, 81 \%$, $94 \%, 98 \%$, and $90 \%$ of scheduled echocardiographic follow-up, respectively. The overall changes in left ventricular hemodynamics and Freestyle aortic valve performance are summarized in Table II. A significant fall in heart rate 6 months after aortic valve replacement was accompanied by a reciprocal increase in global stroke volume index. By 24 months systemic blood pressure had increased significantly. An increase in the flow velocity time integral in the left ventricular outflow tract was noted at 12 months, but the cross-sectional area of the outflow tract remained unchanged. In contrast, the peak flow velocity across the stentless valve fell significantly at 6 months after implantation though its velocity time integral was unchanged. Thus the effective valve orifice area progressively increased from 1.9 to $2.2 \mathrm{~cm}^{2}$. This represented $56 \%$ of outflow tract area at hospital discharge, rising to $67 \%$ by 3 years. This corresponded with a fall in calculated transvalvular mean pressure gradient from 7.5 to $5.2 \mathrm{~mm} \mathrm{Hg}$ (Table II). Less than $5 \%$ of patients had more than trivial aortic regurgitation, and in no patient was aortic regurgitation progres. sive.

By 2 years left ventricular muscle mass index had fallen by $25 \%$ with a corresponding decrease in relative wall thickness ( $\mathrm{T} / \mathrm{R}$ ratio). Meanwhile, myocardial stroke work increased by $60 \%$ in 2 years. However, at 36 to 48 months' follow-up, there was an upswing in $L V$ mass index, $T / R$ ratio, and systolic blood pressure (Table II), despite the fact that neither the valve gradient nor the effective orifice area changed during this period (Tables III and IV).

\section{Discussion}

It is now evident that the nonphysiologic flow profile and residual pressure gradients across mechanical valves and stented bioprostheses are major determinants of late outcome. ${ }^{2-4}$ During normal activity (let alone physical exercise), Doppler-measured mean and peak pressure gradients increase from about 25 and $45 \mathrm{~mm} \mathrm{Hg}$ at rest to 40 and 70 $\mathrm{mm} \mathrm{Hg}$, respectively (symptom-limited Master's 2-step test)., ${ }^{317}$ Prosthesis-related left ventricular pressure increase is now emerging as the principal cause of incomplete regression of myocyte and left ventricular hypertrophy, as well as the progression of interstitial fibrosis. Residual gradients after valve replacement also result in impaired left ventricular diastolic function irrespective of ejection fraction. ${ }^{18}$ This has an important effect on late events including the onset of fatal congestive heart failure. Suboptimal left ventricular function impairs quality of life and increases mortality if aortic reoperation is required. ${ }^{2}$

The new stentless aortic bioprostheses provide improved hemodynamics, rapid resolution of left ventricular hypertrophy, and the promise of improved durability with mitigation from early calcification through biochemical treatments. ${ }^{19-21}$ Superlative valve function and avoidance of anticoagulation with warfarin are compelling arguments for the use of stentless bioprostheses in elderly patients with aortic stenosis. ${ }^{22}$ The structure of the valve and aortic root is highly variable in this group of patients. Many have poststenotic dilatation with a discrepancy between anulus and sinotubular junction dimensions. Others have widespread calcification in the aortic sinuses, often in circumferential distribution around the coronary ostia. There is wide variation in the angle (90 to 180 degrees) between the coronary ostia, and in bicuspid valves the coronary arteries may be diametrically opposite in the aortic root. Despite this, all patients accrue significant benefit from valve replacement with a stentless prosthesis, and we have shown in a consecutive series that the Freestyle porcine aortic root can be used by one technique or another in virtually every patient. The implantation method we describe is reproducible, safe, and effective by accommodating variability in the aortic root. In some patients the ascending aorta must be tailored to the size of the Freestyle outflow, and in the event of very severe 
calcification aortic root replacement may be performed. In our experience this is rarely necessary and collective data show that root replacement is associated with a higher operative mortality (Medtronic submission of collective data to the FDA, 1997).

This consecutive series without patient selection included many elderly patients (NYHA classes IV or $\mathrm{V}$ ) with left ventricular failure, unstable angina, endocarditis, or aortic dissection who were treated on an emergency basis. A hospital mortality of $6 \%$ is not excessive in this context and no deaths were attributed to the use of a stentless rather than a stented aortic prosthesis. ${ }^{23,24}$ With a well-organized operation (median ischemic time of 43 minutes for isolated valve replacement) there is no reason for stentless valve usage to contribute to perioperative mortality. ${ }^{25}$ On the contrary, our median extubation time for all patients was less than 3 hours with hospital discharge to home between 4 and 6 days after the operation. ${ }^{26}$ The fact that 10 patients $(5 \%)$ required a pacemaker after the operation was partly due to pre-existing second-degree heart block (in 2 in whom a pacemaker was used electively) and partly through new complete heart block. This may be caused by injury to the conducting bundle during decalcification of the anulus.

Detailed clinical and echocardiographic follow-up confirms the effectiveness of cardiac and systemic physiologic rehabilitation with a stentless valve. Very low transvalvular gradients translate into rapid resolution of left ventricular hypertrophy, return to NYHA class I, and a low incidence of valve-related complications. ${ }^{9,20}$ In 1 patient who had acute type $A$ dissection 2 years after the operation, the appearance of the Freestyle valve closely resembled that of a normal human valve (Fig. 3), and there was no calcification in the xenograft aortic wall.

Echocardiographic studies show both structural and functional changes in the first 2 years after valve replacement in patients with aortic stenosis. ${ }^{9}$ At the ventricular level, hypertrophy regresses and relative wall thickness falls. This is associated with a striking increase (greater than $60 \%$ ) in external work per unit volume of myocardium. Second, at the outflow tract level the physical dimensions remain constant, but an increase in stroke volume is associated with a wider flow jet and thus greater effective orifice area. These changes have the effect of lowering energy expenditure during ejection by reducing blood flow velocity and acceleration and, thus, transvalvular pressure gradients. ${ }^{9}$ The overall result is a progres- sive improvement in function at both the ventricular and valve level that optimizes coupling between the heart and systemic circulation. These changes, together with a very low incidence of aortic regurgitation, demonstrate the safety and effectiveness of our implantation technique. Similar changes in hemodynamic function have been reported for the Toronto SPV valve (St Jude Medical, Inc, St Paul, Minn), but this valve is a little less versatile and is contraindicated for patients with a size discrepancy between the aortic anulus and sinotubular junction. ${ }^{19}$

Surgery for aortic stenosis is one of medicine's great success stories, but there is increasing realization that the type of valve prosthesis has an important bearing on outcome. Given the unequivocal differences in rehabilitation of the left ventricle after use of a stentless versus stented xenograft, it becomes progressively more difficult to justify the use of first-generation technology.

\section{REFERENCES}

1. Bessone LN, Pypello DF, Hiro SP, el al. Surgical management of aortic valve disease in the elderly: a longitudinal analysis. Ann Thorac Surg 1988;46:264-9.

2. Lindblom D, Lindblom $\mathrm{U}$, Quist J, Lundstrom $\mathrm{H}$. Long term survival rates after heart valve replacement. J Am Coll Cardiol 1990;15:566-73.

3. Jaffe WM, Coverdale HA, Roche $\mathrm{AH}$, et al. Rest and exercise hemodynamics of 20 to $23 \mathrm{~mm}$ allograft, Medtronic Intact (porcine), and St Jude Medical valves in the aortic position. J Thorac Cardiovasc Surg 1990;100:167-74

4. Galloway AC, Colvin SB, Grossi EA, et al. Ten year experience with aortic valve replacement in 482 patients of 70 years of age or older: operative risk and long-term results. Ann Thorac Surg 1990;49:84-9.

5. Cohn LH, Alfred EN, DiSesa VJ, et al. Early and late risk of aortic valve replacement: a 12 -year study of porcine bioprosthetic and tilting disc prosthetic aortic valves. J Thorac Cardiovase Surg 1984;88:695-701.

6. Barratt-Boyes BG, Christie GW. What is the best bioprosthetic operation for the small aortic root? Allograft, autograft, porcine, pericardial, stented or unstented. J Card Surg 1994;9:158-64.

7. Westaby S, Katsumata T, Houel R, Shinfeld A. Stentless xenograft repair of the dissected aortic root. Ann Thorac Surg 1998;65:1448-50

8. Kon ND, Westaby S, Amarasena N, ct al. Comparison of implant techniques using the Freestyle stentless porcine aortic valve. Ann Thorac Surg 1995;59:857-62.

9. Jin XY, Westaby S, Gibson DG, et al. Left ventricular remodelling and improvement in Freestyle stentless valve hemodynamics. Eur J Cardiothorac Surg 1997;12:63-9.

10. Lewis JF, Kuo LC, Nelson JG, et al. Pulsed Doppler echocardiographic determination of stroke volume and cardiac ontput: clinical validation of two new methods using the apical window. Circulation 1984;70:425-31.

11. Chambers J, Shah PM. Recommendation for the cchocardio- 
graphic assessment of replacement heart valves. J Heart Valve Dis 1995;4:9-13.

12. Sahn DJ, DeMaria A, Kisslo J, Weyman A. The committee on M-mode standardization of American Society of Echocardiography: recommendations regarding quantitation in $\mathrm{M}$ mode echocardiography: results of a survey of echocardiography measurements. Circulation 1978;58:1072-83.

13. Devereux RB, Alonso DR, Lutas EM, et al. Echocardiographic assessment of left ventricular hypertrophy: comparison to necropsy findings. Am J Cardiol 1986;57:450-8.

14. Dubin J, Wallerson DC, Cody RJ, Devereux RB. Comparative accuracy of Doppler echocardiographic methods for clinical stroke volume determination. Am Heart J 1990;120: 116-23.

15. Dodge HT, Baxley WA. Left ventricular volume and mass and their significance in heart disease. Am J Cardiol 1969;23 528-37.

16. Minitab Inc. MINITAB reference manual release 11 . Windows version. Philadelphia: Minitab Inc. 1996. p. 3.3-3.6

17. Dumesnil JG, Yoganathan AP. Valve prosthesis hemodynamics and the problems of high transprosthetic pressure gradients. Eur J Cardiothorac Surg 1992;6(suppl):34-8.

18. Vallari B, Vassali G, Morira ES, et al. Normalization of diastolic dysfunction in aortic stenosis late after valve replacement. Circulation 1995;91:2353-8.

19. David TE, Feindel CM, Bos J, et al. Aortic valve replacement with stentless porcine aortic valve: a six-year experience. J Thorac Cardiovasc Surg 1994;108:1030-6.

20. Jin XY, Zhang ZM, Gibson DG, et al. Effects of valve substitute on changes in left ventricular function and hypertrophy after aortic valve replacement. Ann Thorac Surg 1996;62:683-90.

21. Grodd $C$, Hasinger $W$, Mair $R$, et al. Aortic valve replacement: Is the stentless xenograft an alternative to the homograft? Early results of a randomized study. Ann Thorac Surg 1995;60:S418-21.

22. Sintek CF, Fletcher AD, Khonsari S. Stentless porcine aortic root: Valve of choice for the elderly patient with small aortic root? J Thorac Cardiovasc Surg 1995;109:871-6.

23. Aberg T. Socio-economic considerations in surgery for elderly patients. In: Piwnica A, Westaby $S$, editors. Surgery for acquired aortic valve disease. 1st ed. Oxford: Isis Medical Media; 1997. p. 327-33.

24. Arank SF, Rizzo RJ, Couper GS, et al. Aortic valve replacement in the elderly: effect of gender and coronary artery disease on operative mortality. Circulation 1993;88:17-23.

25. Scott WC, Miller DC, Haverich A, et al. Determinants of operative mortality for patients undergoing aortic valve replacement. J Thorac Cardiovasc Surg 1985;89:400-13.

26. Westaby S, Pillai R, Parry A, et al. Does modern cardiac surgery require conventional intensive care? Eur J Cardiothorac Surg 1993; 7:313-8. 